\title{
Caracterização do entorno das moradias estudantis em Salvador.
}

Characterization of the urban context of student housing in Salvador.

\section{Sabrina Sacramento*, Yuri Oliveira**, Aline Barroso**, Mayara Araújo ${ }^{\star \star \star *}$}

*Graduanda em Arquitetura e Urbanismo pela Universidade Federal da Bahia (UFBA). Bolsista de Iniciação Científica no grupo de pesquisa Lugar Comum da Faculdade de Arquitetura da UFBA, no qual desenvolveu pesquisa sobre moradia estudantil e atualmente pesquisa sobre a mobilidade urbana dos estudantes, sabrinacsacrameto@gmail.com

**Bacharel Interdisciplinar em Artes pela Universidade Federal da Bahia (UFBA) e graduando em Arquitetura e Urbanismo pela UFBA. Bolsista de Iniciação Científica no grupo de pesquisa Lugar Comum da Faculdade de Arquitetura da UFBA, no qual desenvolve atualmente pesquisa sobre o perfil socioeconômico do estudante contemplado com o auxilio transporte, yurioliver90@gmail.com

***Arquiteta e urbanista pela Universidade Federal do Ceará, Mestre em Engenharia Civil pela Universidade Federal do Rio Grande do Sul, Doutora em Urbanismo e Ordenação do Território pela Universidad Politécnica de Madrid, professora adjunta da Faculdade de Arquitetura da UFBA e professora colaborada no Programa de Pós-graduação em arquitetura e urbanismo (PPGAU), alinebarroso@gmail.com

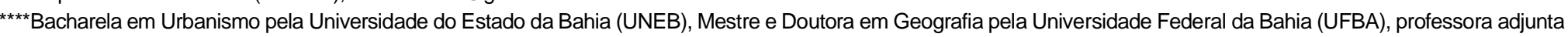
da Faculdade de Arquitetura da UFBA, maiaraujo2006@gmail.com

\section{Palavras-chave:}

Assistência estudantil.

Direito à cidade.

Equipamentos urbanos.

\section{Keywords:}

Right to the city.

Student assistance.

Urban equipments.

\section{Resumo}

cia da moradia e de sua localização para o acesso a equipamentos básicos, este artigo objetivou mapear e analisar o entorno das moradias estudantis em Salvador. Foi priorizada a análise dos equipamentos de saúde e estabelecimentos comerciais do tipo farmácia, mercado e reprografia. A pesquisa iniciou-se com o entendimento da política de assistência estudantil no Brasil especialmente em Salvador. Foram realizados levantamentos, mapeamentos e visitas in loco das moradias. A primeira análise considerou a acessibilidade destes estudantes à UFBA, a partir da distância entre essas moradias e a referida instituição, a segunda análise foi com relação à presença dos equipamentos, acima citados, no entorno das moradias estudantis, para isso, foram estabelecidos raios de caminhabilidade que indicavam a distância média confortável para alcançar os equipamentos. Pode-se concluir que a maioria das moradias estudantis em Salvador encontrava-se em contextos urbanos com boa oferta dos equipamentos analisados e que a política de assistência estudantil deve levar em consideração, para além da qualidade da moradia, sua localização, visando ao acesso dos estudantes a equipamentos urbanos, e consequentemente contribuindo para o direito à cidade desses indivíduos.

\section{Abstract}

Understanding the importance of housing and its location for access to basic equipment, this article aims to map and analyze the urban context of student housing in Salvador, for that priority was given to the analysis of: health equipment and commercial establishments of the type pharmacy, market and reprography. The research started with the unders tanding of student assistance policy in Brazil and especially in Salvador Mapping and visits in loco of student housing in the city were carried out. The first analysis considers the accessibility of these students to UFBA, based on an analysis of the distance between these houses and the institution, the second one analyzes the presence of the aforementioned equipment in the vicinity of the student houses, for this, walking radii were established that indicate the average comfortable distance to reach each equipment. It can be concluded that the majority of student housing in Salvador is inserted in urban contexts with a good supply of the analyzed equipment and that the student assistance policy must aiming at the opportunity students access to urban equipment, and consequently contributing to the right to the city of these individuals. 


\section{Introdução}

Este artigo é um dos produtos gerados a partir do projeto de pesquisa "Moradia Estudantil: mapeamento da realidade do habitar na UFBA"1, no qual foram realizados levantamento e caracterização das moradias estudantis existentes em Salvador, tanto as mantidas pela Universidade Federal da Bahia (UFBA) quanto as que possuem relação com prefeituras de outros municípios do estado e com associações estudantis. O tema da moradia estudantil merece atenção especial em Salvador, pois não foram encontrados estudos sistematizados sobre essas moradias na cidade. Assim, a pesquisa torna-se importante para o conhecimento sobre a realidade atual desse serviço que é um direito dos estudantes.

O objetivo geral deste artigo é entender os contextos urbanos das moradias estudantis existentes em Salvador a partir dos principais serviços de interesse dos estudantes. Os serviços escolhidos para serem analisados foram os equipamentos de saúde, e os estabelecimentos comerciais do tipo farmácia e mercado. Esses serviços são importantes para o cotidiano de qualquer cidadão pois dão suporte às necessidades de saúde e alimentação². Também acrescentamos o levantamento de serviços de reprografia ${ }^{3}$ como de interesse dos estudantes, haja vista a realidade estudantil com constante necessidade deste tipo de serviço.

Com vistas a alcançar o objetivo proposto, foi realizada inicialmente uma revisão bibliográfica sobre temáticas e metodologias de estudos com o mesmo tipo de abordagem, subsidiando a construção das análises a serem realizadas. Em paralelo foi realizado o levantamento e caracterização das moradias estudantis. Para dar conta

${ }^{1}$ Pesquisa desenvolvida pelo grupo Lugar Comum da Faculdade de Arquitetura da UFBA.

${ }^{2}$ Entendemos que para analisar o entorno de uma moradia, é necessário levar em consideração a presença de diversos outros equipamentos além dos mencionados. No entanto, devido a limitações da pesquisa, foi necessário restringir a análise a equipamentos de uso cotidiano.

${ }^{3}$ Embora tenhamos conhecimento de que o serviço de reprografia se relaciona ao conjunto de meios e ou departamento de reprodução de documentos encontrado em instituições e/ou empresas públicas ou privadas, para serviços como: fotocópia, microfilmagem, heliografia, etc., no âmbito deste trabalho nos referimos a ela apenas na perspectiva da fotocópia e impressão de material acadêmico, serviços essenciais para a rotina estudantil. Respeitando o estabelecido no art. 29, Capítulo III - Dos serviços essenciais para a rotina estudantil. Respeitando o estabelecido no art. 29, Capitulo III - Dos Direitos Patrimoniais do Autor e de sua Duração - da Lei Federal ํㅜ 9.610, de 19 de fevereiro de 1998 , que regula os direitos autorais, do qual depreendemos que a reprodução parcial ou integra de uma obra, depende de autorização prévia e expressa do(a) autor(a). dessa etapa, inicialmente foram feitas buscas online em sites institucionais, blogs e redes sociais das moradias estudantis, visando identificar quais são e onde estão localizadas. Também foi importante o contato estabelecido com membros e exmembros da Associação de Casas de Estudantes da Bahia (ACEB) e do grupo Viva Gente $^{4}$, que ajudaram na complementação das informações. Por fim, foi elaborado um levantamento dos sujeitos-chaves envolvidos na temática da moradia estudantil, como agentes institucionais das prefeituras do interior do estado, presidentes das moradias estudantis e ex-moradores, a fim de se obter informações sobre a localização destas moradias.

Concluído o levantamento inicial, foram realizadas visitas para aplicação de questionário, no período de setembro de 2018 a março de 2019. No decorrer desta aplicação, muitas vezes descobriu-se outras moradias, e essas foram acrescentadas ao levantamento. O questionário aplicado possuía perguntas referentes à estrutura física, organização e administração da moradia e caracterização do seu entorno.

Após visita e aplicação de questionários, os dados coletados sobre a localização das moradias e seu entorno alimentaram o mapeamento realizado através do software Google Earth $h^{5}$. Tal mapeamento foi complementado com dados da pesquisa coordenada pelo professor Juan Pedro Moreno Delgado ${ }^{6}$ e por atualizações dos pesquisadores através de dados do Google Earth. As informações foram inseridas no software através de ícones estabelecidos para as moradias e para cada tipo de equipamento, e organizados de acordo com os bairros e as localidades ${ }^{7}$ estudadas.

${ }^{4}$ Coletivo de jovens da Bahia que realizam discussões sobre temáticas feministas, do povo negro LGBTQI+ e outras nas moradias estudantis.

${ }^{5}$ Programa desenvolvido e distribuído pela empresa Google.

${ }^{6}$ Professor e pesquisador do Departamento de Engenharia de Transportes e Geodésia da Universidade Federal da Bahia.

7 O livro "O Caminho das Águas em Salvador", define bairro como uma unidade territorial, com densidade histórica e relativa autonomia no contexto urbano-ambiental, que incorpora as noções de sidade historica e relativa autonomia no contexto urbano-ambiental, que incorpora as noçoes de identidade e pertencimento dos moradores que o constituem; que utilizam os mesmos equipamentos e serviços comunitários; que mantêm relações de vizinhança e que reconhecem seus limites pelo mesmo nome. Por localidade, o estudo define que é uma porção menor do território, inserida parcia ou totalmente em um bairro, sem centralidade definida e que apresenta características socioeconômicas similares. A localidade pode ser um loteamento, um conjunto habitacional, uma pequena ocupação informal ou uma ocupação ao longo de uma avenida. 
Assim sendo, o artigo é composto por uma seção metodológica sobre a forma que os equipamentos foram analisados, trazendo uma referência sobre o assunto e estabelecendo critérios para análise dos dados obtidos e mapeados. Em seguida, é apresentada a localização das moradias estudantis em Salvador e a análise de seus entornos.

\section{Metodologia}

A análise e interpretação dos dados obtidos ocorreram com base nos critérios construídos por Castello (2008), que busca entender as relações que ocorrem no espaço circunvizinho de uma edificação, através de características como o uso e os equipamentos existentes. Castello (2008) estabelece parâmetros de análise para diferentes equipamentos (Figura 1), entre os quais trabalharemos com Tipos de Equipamentos e Local/Distância, cuja compreensão deteve-se sobre o raio de caminhabilidade.

Assim sendo, o raio de caminhabilidade indicará a distância máxima confortável para o deslocamento das pessoas, até cada tipo de equipamento. Trata-se então, do quanto uma pessoa se desloca no entorno de sua moradia para acessar equipamentos de saúde, farmácia, mercado e reprografia. A análise levando em consideração os raios de caminhabilidade será vista na sessão intitulada "Análise do entorno das moradias" com a adoção dos raios de 400 metros e de 800 metros.

Nesse sentido é importante esclarecer que os parâmetros de localização e distância construídos por Castello (2008) são estabelecidos a partir de escalas de análise. No caso, a de Vizinhança é a primeira escala e nela deve existir equipamentos e práticas que complementam a habitação, formando um ambiente que incentiva a interação dos moradores com o lugar. Ela seria então, um espaço habitacional equipado com serviços e comércio de necessidade de acesso cotidiano. A segunda escala territorial é a do Bairro, com equipamentos, serviços, mobiliário urbano e relações com a natureza. É uma escala mais ampla, na qual os equipamentos demandam um público maior que o da escala de vizinhança. A última escala territorial é a Cidade, com sua diversidade de usos, que contemplam todos os contextos anteriores.

${ }^{8}$ No que diz respeito ao agente provedor do equipamento, foram considerados apenas os
Na escala da Cidade os equipamentos são de maior porte pois possuem abrangência urbana ou regional.

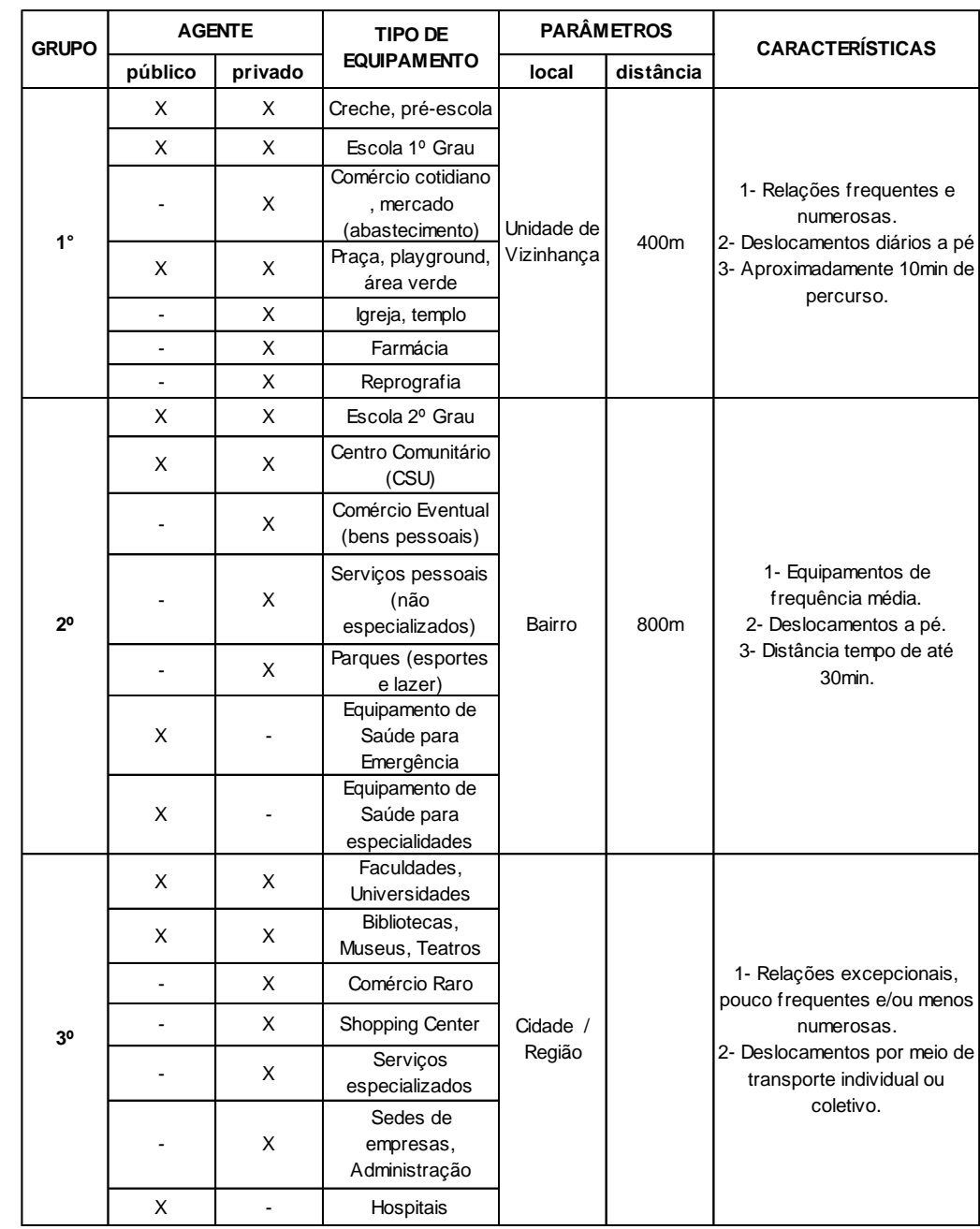

Figura 1: Equipamentos urbanos: grupos hierárquicos, parâmetros de localização e características gerais ${ }^{8}$. Fonte: Acervo dos autores adaptado de Castello (2008).

equipamentos de saúde cujo agente provedor é o setor público, devido ao público-alvo. Para os 
Para a análise de Salvador, adotou-se o raio de caminhabilidade de 400 metros para os equipamentos mercado, farmácia e reprografia, pois se configuram como equipamentos da unidade de vizinhança que devem ser acessados frequentemente e a pé.

Outro importante esclarecimento é que em muitos casos, as moradias estão localizadas muito próximas (até 200 metros de distância), por isso, adotou-se uma análise simplificada desses contextos, sendo consideradas todas dentro do mesmo raio de caminhabilidade, e denominadas a partir do nome do bairro ou localidade. Quando não foi possível esse agrupamento, as moradias foram analisadas isoladamente e também denominadas conforme do bairro ou localidade. Por último, em bairros ou localidades que existem mais de uma análise, cada uma delas foi nomeada conforme o bairro ou localidade e numerada.

Além disso, outra análise realizada foi para o entendimento da relação dessas moradias com a UFBA, para tanto foram estabelecidos contextos de análise, a partir da Reitoria e do Campus Ondina, campi que concentram a maioria dos cursos da universidade. Com base no que Castello (2008) considera como equipamentos de influência em escala de cidade/região, foi fixado o raio de $1,5 \mathrm{~km}$ como o primeiro contexto de análise e foram estabelecidas mais duas escalas de análise: a de $3 \mathrm{~km}$, intermediária, e a de $6 \mathrm{~km}$ que abarca todas as moradias levantadas.

\section{Moradias Estudantis}

\section{Um breve histórico da política de assistência estudantil}

Na década de 1970 com a expansão do ensino superior, a necessidade pela assistência estudantil cresceu. Nesta mesma década, como forma de dar suporte aos estudantes, o governo federal criou o Departamento de Assistência ao Estudante (DAE), que concedia bolsas de estudo e oportunidades de bolsas-trabalho, assim como o acesso a programas que tinham como prioridade a assistência médicoodontológica, alimentação e moradia. Na década de 1980 o DAE foi extinto, fragmentando a assistência estudantil (IMPERATORI, 2017).

equipamentos farmácia, mercado e reprografia foram considerados os que possuem agente provedor do setor privado, pois são predominantemente ofertados por este setor.

${ }^{9}$ Essa assistência estudantil da década de 1940 da UFBA, não se referia à política estudantil tal qual temos hoje, mas há de se destacar este pioneirismo, sendo nos anos posteriores, incorporadas novas moradias e modalidades de auxílio que permitiram outras formas de assistência estudantil.
Somando-se a extinção do DAE, ocorreu no fim da década de 1990 a aprovação da Lei de Diretrizes e Bases da Educação (LDB), que isentou do Estado a obrigatoriedade de conceder recursos para a assistência estudantil (CUNHA, 2017).

Após quase uma década sem avanços quanto à discussão da assistência estudantil, a partir dos anos 2000, de acordo com Baumgartner (2016), ocorreu um fenômeno de expressão nacional de grande espraiamento das universidades federais brasileiras, ocasionando um significativo impacto no acesso ao ensino superior. Os resultados dessa expansão e reestruturação da educação superior no Brasil, de um lado foram visíveis nos espaços intraurbanos das cidades em razão do forte impacto econômico, político e cultural trazido pelos campi dessas universidades. Por outro, também repercutiu na retomada do debate em torno da assistência estudantil.

Assim sendo, destaca-se a implementação do Plano Nacional de Assistência Estudantil (PNAES), decretado em 2010, que definiu como alvos prioritários das políticas de assistência estudantil, estudantes cujos grupos familiares tivessem renda de até um e meio salário mínimo (IMPERATORI, 2017; ANDIFES, 2019).

Segundo pesquisa realizada pela Andifes (2019), nos anos de 2010, 2014 e 2018, o número de estudantes das Instituições Federais de Ensino Superior (IFES) cresceu de aproximadamente 656 mil para 1.200.300 milhões, um aumento de 43,65\%. Neste mesmo período, houve um aumento na quantidade geral de estudantes das IFES que se encaixam como alvos da assistência estudantil, sendo na região Nordeste cerca de $78,3 \%$ dos estudantes matriculados.

Ainda no que tange à assistência estudantil, afirmações presentes em Costa e Oliveira (2012) salientam o pioneirismo da Bahia tratando dessa perspectiva, isso porque, em $1947^{9}$, a UFBA adquire um casarão no Corredor da Vitória, que se tornou a primeira moradia estudantil da Bahia. Inaugurando em 1956 a Residência Universitária Feminina da UFBA e no ano de 1962 uma moradia para estudantes estrangeiros, que se transformou na Residência Universitária II.

Atualmente, a assistência estudantil da UFBA compreende ações voltadas à moradia, transporte alimentação, saúde, entre outros. 
Os referidos autores apontam que até o final da década de 1960, não havia tanto fluxo de estudantes para a capital. Entretanto, na década de 1970, com a expansão nacional do ensino superior e a necessidade de alguns estudantes que migravam para Salvador, foram criadas algumas moradias estudantis de municípios do interior do estado, dentre as quais podemos citar aquelas que foram levantadas através desta pesquisa: Ipirá, Boquira, Macaúbas, Itaberaba, Uibaí, Irecê e Nova Canaã.

Na década de 1980, juntamente ao crescimento da cidade de Salvador e ao avanço imobiliário, muitos estudantes migraram em busca de crescimento acadêmico e profissional. Ainda na década de 1980, através de iniciativas de apoiadores solidários, de algumas prefeituras e de instituições de ensino superior que alugaram, adaptaram ou construíram novas moradias estudantis, foram garantidas novas oportunidades de permanência e de acesso ao ensino superior a estudantes que se deslocam para a capital (COSTA; OLIVEIRA, 2012).

Os referidos autores, somado aos levantamentos desta pesquisa, apontam que a partir da necessidade dos estudantes, surgiram nesse período, moradias como as dos municípios de Itapetinga, Barra e Ibiquera, havendo, inclusive, um marco histórico importante nesta década que é articulação entre as moradias estudantis, dos diferentes municípios, no Movimento das Casas de Estudantes (MCE).

\section{Situação atual das moradias estudantis em Salvador}

Diante do contexto apresentado, no qual a moradia estudantil faz parte de uma política de assistência ao estudante, torna-se importante entender sua situação atual em Salvador. Na pesquisa "Moradia estudantil: mapeamento da realidade do habitar na UFBA", realizada entre 2018 e 2019, foi confirmada a existência de 55 moradias estudantis em Salvador, das quais representantes de 48 responderam ao questionário - cinco são mantidas e administradas pela UFBA e 43 são ligadas às prefeituras de municípios do interior da Bahia e às associações estudantis. A distribuição espacial destas moradias estudantis é observada na Figura 2.

O conhecimento sobre a localização destas moradias permitiu a realização do mapeamento apresentado neste artigo, no qual analisamos o entorno e a oferta de serviços para as 48 moradias que foram visitadas. A aplicação do questionário não contemplou todas as moradias estudantis listadas devido à ausência de retorno nos contatos estabelecidos com moradores, representantes e instituições gestoras.

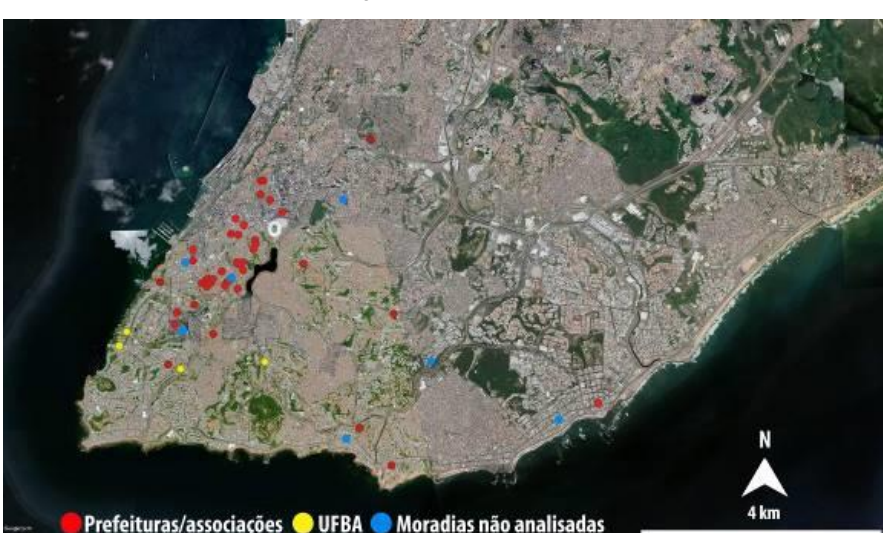

Figura 2: Localização das moradias estudantis em Salvador. Fonte: Acervo dos Autores.

Conforme explicado na metodologia, foram inseridos os raios de $1,5 \mathrm{~km}$, 3km e $6 \mathrm{~km}$ (Figura 3), que correspondem às escalas de análise para entendimento da relação de localização das moradias estudantis com a UFBA, tendo como centro de raio a Reitoria e o Campus Ondina.

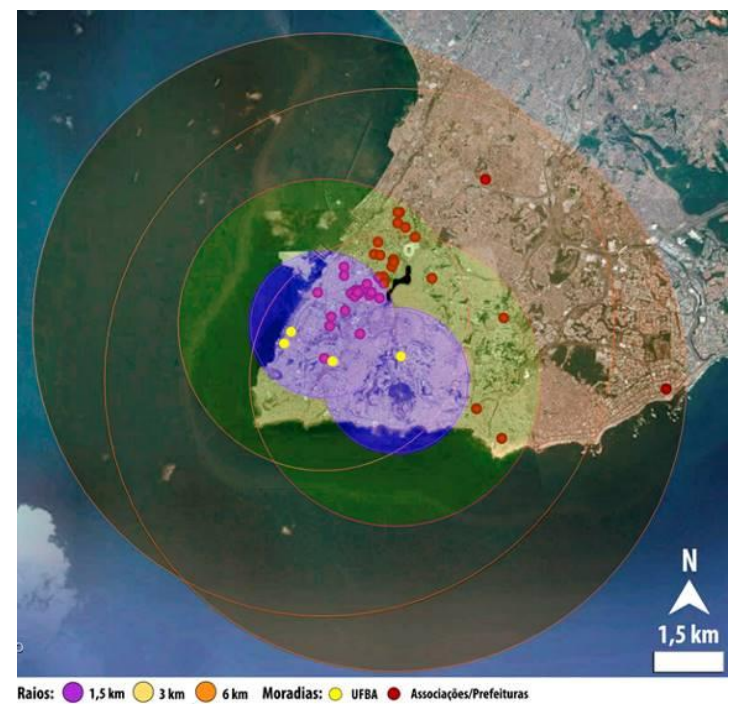

Figura 3: Localização das moradias estudantis em Salvador com relação à UFBA. Fonte: Acervo dos Autores. 
É possível perceber que a maioria das moradias estudantis se concentra dentro dos raios de $1,5 \mathrm{~km}$ e $3 \mathrm{~km}$ da UFBA.

\section{Análise do entorno das moradias}

Após a compreensão de como as moradias estudantis estão inseridas na cidade, passa-se para a análise do entorno destas moradias que será apresentada nesta sessão.

A análise foi realizada a partir do quantitativo de cada tipo de equipamento nos contextos das moradias ou dos grupos de moradias, conforme explicado na metodologia. Nesse sentido, é apresentando o contexto com a melhor e/ou pior oferta de cada equipamento. É importante ressaltar que foi considerada apenas a quantidade de equipamentos e não a qualidade dos serviços por eles prestados.

\section{Equipamentos de saúde}

No que se refere à discussão sobre os equipamentos de saúde, foram analisadas as informações quanto à sua localização, e como dito anteriormente, somente levando em consideração a quantidade e não a qualidade do serviço.

As informações sobre a localização dos equipamentos de saúde utilizadas no mapeamento foram obtidas através dos sites da Secretaria Municipal da Saúde de Salvador (SMS) e da Secretaria da Saúde do Estado da Bahia (Sesab). Além da localização dos equipamentos é importante entender que há diferenças entre eles. Por isso, foi necessário classificá-los de acordo com o tipo de atendimento que ocorre em cada um dos equipamentos. Sendo definido: equipamento para atendimento de emergência $^{10}$, equipamento para atendimento especializado ${ }^{11}$ e hospitais ${ }^{12}$.

Para os equipamentos de saúde classificados como de emergência e de atendimento especializado, foi adotado o raio de caminhabilidade de 800 metros, que pode ser feito de modo a pé ou por meio de transporte individual e público coletivo (CASTELLO, 2008). Entretanto, é importante considerar que o hospital deve ser

${ }^{10}$ Equipamentos com serviço de urgência e emergência com funcionamento ininterrupto: Unidades de Pronto Atendimento (UPA), UPA 24h, Pronto Atendimento (PA) e Unidade de Atendimento Odontológico (UAO) classificado na escala de cidade/região, pois é um equipamento importante cujo acesso não é rotineiro, não sendo obrigatória sua presença em cada bairro, por isso, ele não foi incluído nas deficiências de cada contexto. Para finalizar, entendemos que a existência de um hospital qualifica o bairro e/ou localidade, por isso este equipamento foi considerado sempre como uma potencialidade.

A Figura 4 apresenta a distribuição dos equipamentos, por categoria, em cada contexto analisado ${ }^{13}$. No desenvolvimento das análises, verificamos que o equipamento para atendimento especializado é o mais presente dentro dos contextos estudados. Em contrapartida, os equipamentos de emergência não estão sendo ofertados na maioria dos grupos de moradias.

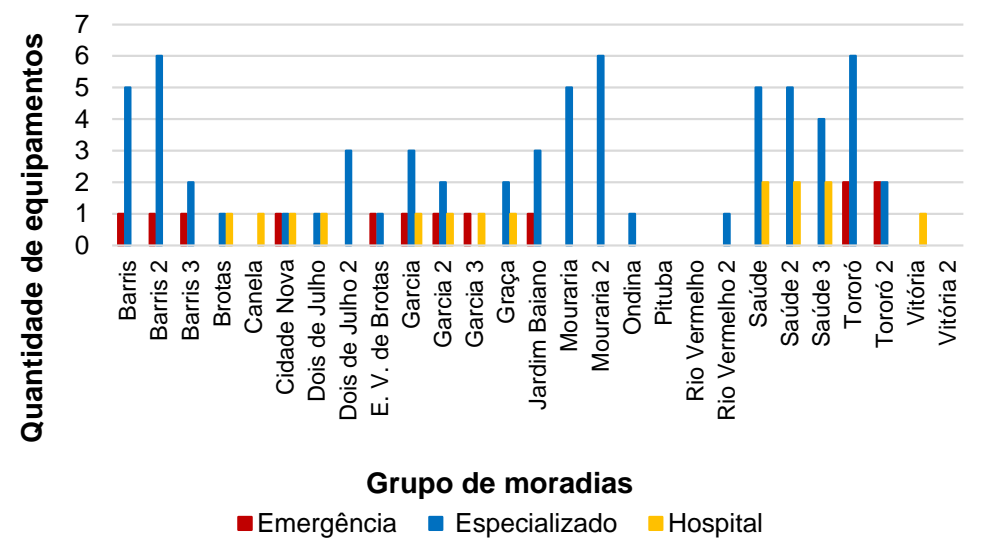

Figura 4: Quantidade de equipamentos de saúde segundo os contextos das moradias. Fonte: Acervo dos Autores.

É importante salientarmos algumas peculiaridades encontradas nesta análise. Por exemplo, os contextos Canela e Vitória, possuem apenas um hospital em seu

${ }^{11}$ Equipamentos com serviço de exames, consultas médicas com especialidades: Unidade de Saúde da Família (USF), Unidade Básica de Saúde (UBS), Multicentros e Centros de Especialidades Odontológicas (CEO).

${ }^{12}$ Equipamentos com atendimento de média e alta complexidade.

${ }^{13}$ Conforme discutido na metodologia. 
entorno, entretanto, este é o Hospital Universitário Professor Edgard Santos (HUPES), gerido pela UFBA e que realiza atendimento especializado aos estudantes da universidade. O HUPES é então de grande importância para os residentes das moradias estudantis.

Notamos também que os contextos Cidade Nova, Garcia e Garcia 2 destacam-se pela presença dos três equipamentos de saúde analisados, embora apenas os hospitais no entorno das moradias localizadas na Saúde disponham de atendimento de emergência.

Ainda de acordo a Figura 4 e considerando os equipamentos de emergência e os de atendimento especializado, como os que possuem maior frequência de uso pelos moradores do seu entorno, constatamos que os grupos de moradias Barris, Barris 2, Barris 3, Cidade Nova, Engenho Velho de Brotas, Garcia, Garcia 2, Jardim Baiano, Tororó e Tororó 2 são os mais bem servidos, por possuírem pelo menos um equipamento para atendimento de especialidades e um equipamento de emergência dentro do raio de caminhabilidade adotado.

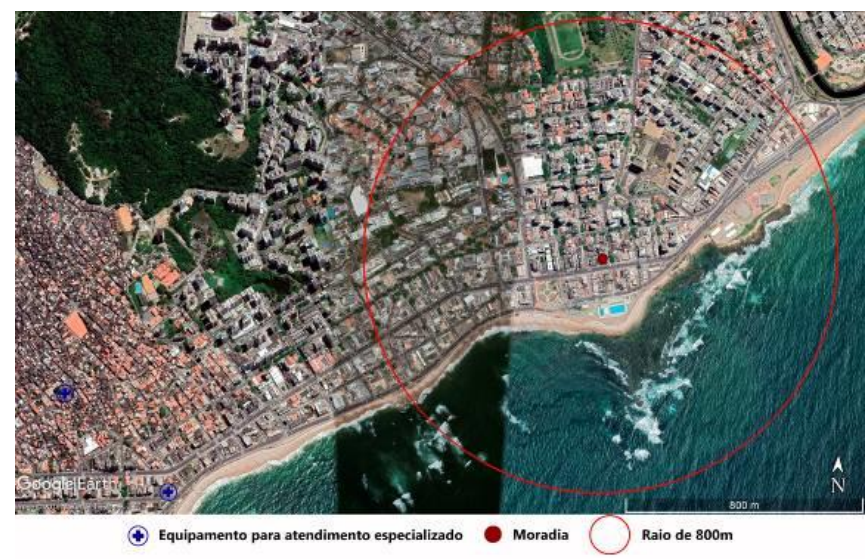

Figura 5: Equipamentos de saúde mais próximos da moradia do contexto Pituba. Fonte: Acervo dos Autores.

${ }^{14} \mathrm{O}$ contexto Pituba foi escolhido para representar a pior situação pois o equipamento de saúde mais próximo da moradia está a 1660 metros, enquanto que no contexto Rio Vermelho, o equipamento de saúde mais próximo está a 870 metros da moradia estudantil.
Além disso, conforme demonstrado na Figura 5, Pituba foi considerado o pior contexto em relação a oferta dos equipamentos de saúde ${ }^{14}$, pois não dispõe de nenhum equipamento público no entorno estudado. Embora, trate-se de um bairro com ocupação residencial e com grande oferta de serviços, dentre eles, o de saúde, o equipamento de saúde público mais próximo encontra-se no raio de aproximadamente 1660 metros, a partir da moradia estudantil do contexto Pituba.

\section{Farmácias}

Conforme detalhado na metodologia, a farmácia foi considerada como um equipamento necessário dentro da unidade de vizinhança, logo, com um raio de caminhabilidade de 400 metros. Na análise da oferta dos mesmos, por grupos de moradia, verificamos que este equipamento está presente em todos os contextos analisados (Figura 6).

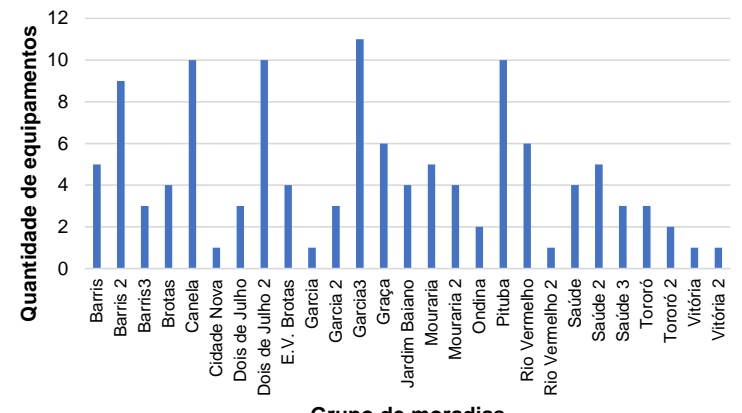

Grupo de moradias

Figura 6: Quantidade de equipamentos farmácia segundo os contextos de moradias. Fonte: Acervo dos Autores.

Destacamos o contexto Garcia 3, que possui onze equipamentos deste tipo em seu entorno. Em contrapartida, as moradias estudantis menos providas de farmácias em seu entorno são as dos contextos Cidade Nova, Garcia, Rio Vermelho 2, Vitória 
e Vitória 2, possuindo apenas uma farmácia dentro do raio de caminhabilidade, conforme ilustrado na Figura 7, que apresenta o exemplo do Rio Vermelho 2.

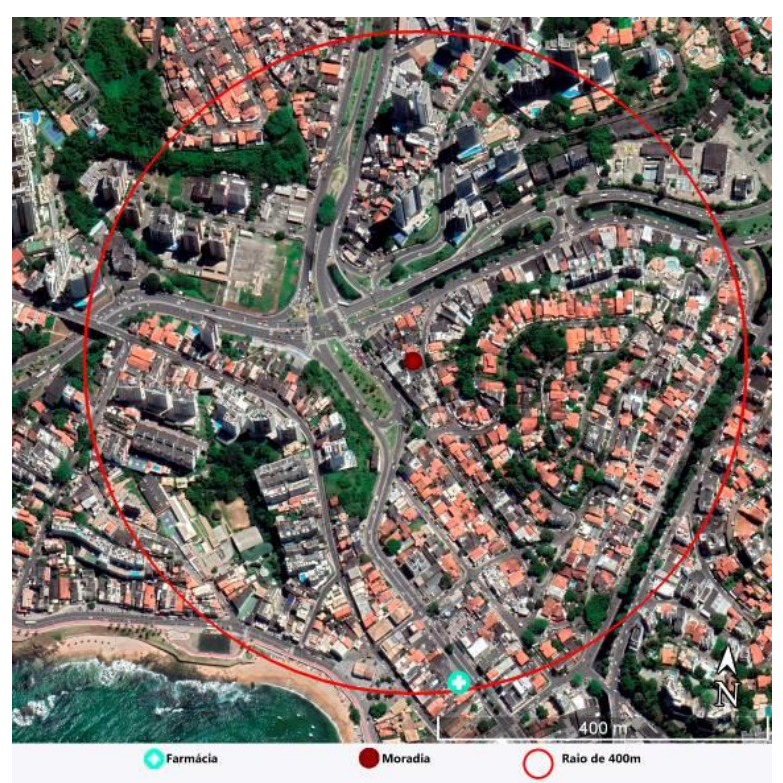

Figura 7: Oferta de farmácias no entorno da moradia Rio Vermelho 2. Fonte: Acervo dos Autores.

\section{Mercados}

Para a análise do equipamento mercado, consideramos que o mesmo deve estar presente em cada unidade de vizinhança, logo, com um raio de caminhabilidade de 400 metros. Através da Figura 8 percebemos que todos os grupos de moradias, possuem pelo menos um equipamento deste tipo em seu entorno.

Notamos que as moradias presentes nos Barris são as de melhor situação, pois Barris e Barris 3 possuem dez equipamentos deste tipo em seu entorno e Barris 2 possui 13 equipamentos. A situação descrita sobre o bairro Barris é mostrada na Figura 9.
Sabrina Sacramento, Yuri Oliveira, Aline Barroso e Mayara Araújo Caracterização do entorno das moradias estudantis em Salvador

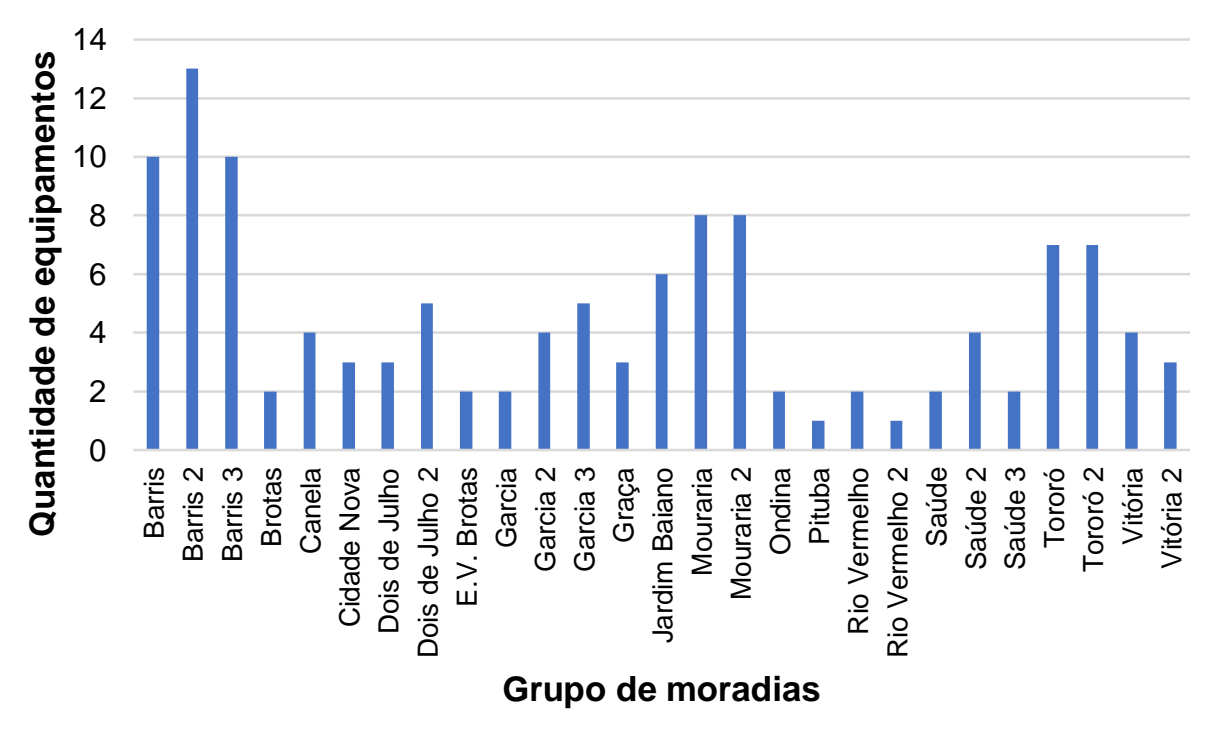

Figura 8: Quantidade de equipamentos de mercado segundo os contextos de moradias. Fonte: Acervo dos Autores.

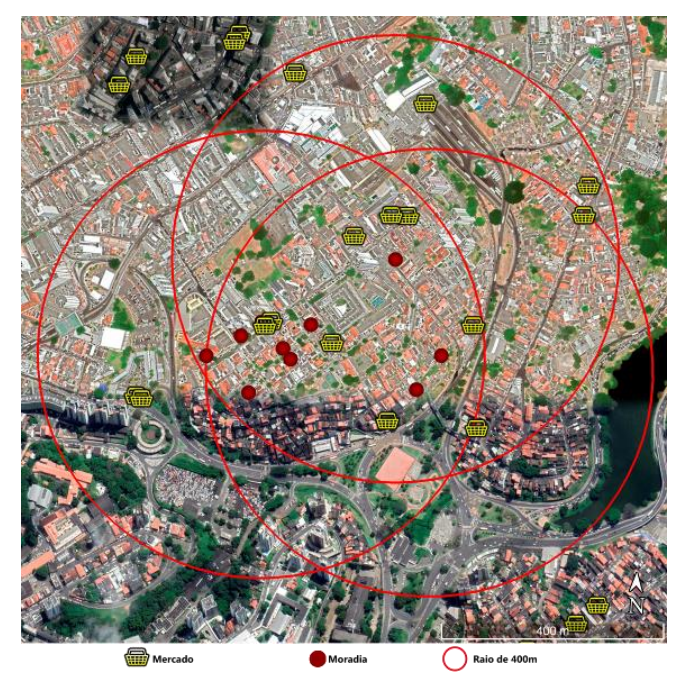

Figura 9: Oferta de mercados no entorno dos grupos de moradias Barris, Barris 2 e Barris 3. Fonte: Acervo dos Autores. 
Nos grupos de moradia com menor presença do equipamento de mercado, Pituba e Rio Vermelho 2, observamos que os equipamentos mapeados são equipamentos de grande porte, com demanda em escala de bairro e de região. Portanto, mesmo com a situação de ter apenas um equipamento disponível, há variedade nos produtos e maior escala de alcance. Enquanto que nos grupos de moradias com maior oferta de equipamentos, o comércio é mais dedicado à escala de vizinhança, possibilitando uma grande quantidade de equipamentos de pequeno porte.

\section{Reprografia}

Apesar de termos ciência que o desrespeito à Lei Federal nำ 9.610, de 19 de fevereiro de 1998, que regula os direitos autorais e, consequentemente, a reprodução parcial ou integral de obras, ainda é frequente em estabelecimentos de reprografia que não possuem uma relação com os campi universitários, decidimos mapear os referidos estabelecimentos, primeiro por considerar a importância da impressão de trabalhos e material acadêmico em geral para a rotina estudantil, e segundo porque entendemos que este mapeamento pode subsidiar futuras análises críticas, e específicas, sobre o referido serviço e seu uso pelo estudante universitário, objetivos que não fizeram parte desta pesquisa inicial.

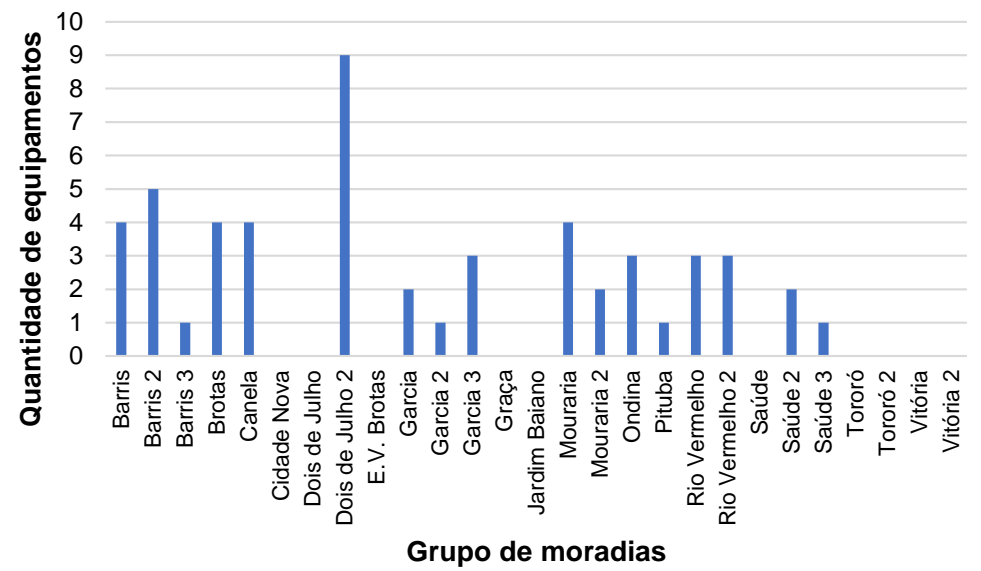

Figura 10: Quantidade de equipamentos de reprografia segundo os contextos das moradias. Fonte: Acervo dos Autores.
Dito isso, para análise da oferta do equipamento de reprografia (Figura 10), utilizamos o raio de caminhabilidade de 400 metros, pois consideramos que este equipamento é necessário dentro da unidade de vizinhança.

Comparando-o com os demais equipamentos analisados, é o menos presente no entorno das moradias estudantis. Entretanto, isto não foi considerado como um fator negativo, pois este serviço é disponibilizado dentro dos campi da universidade.

Destacamos, da leitura dos dados contidos na Figura 10, o grupo de moradias Dois de Julho 2, que dispõe de 9 equipamentos de reprografia em seu entorno. A grande oferta deste tipo de equipamento pode resultar da presença da centralidade que é a Avenida Sete de Setembro e a Praça da Piedade, com grande concentração de comércio e serviços. A situação descrita sobre o contexto Dois de Julho 2 é mostrada na Figura 11.

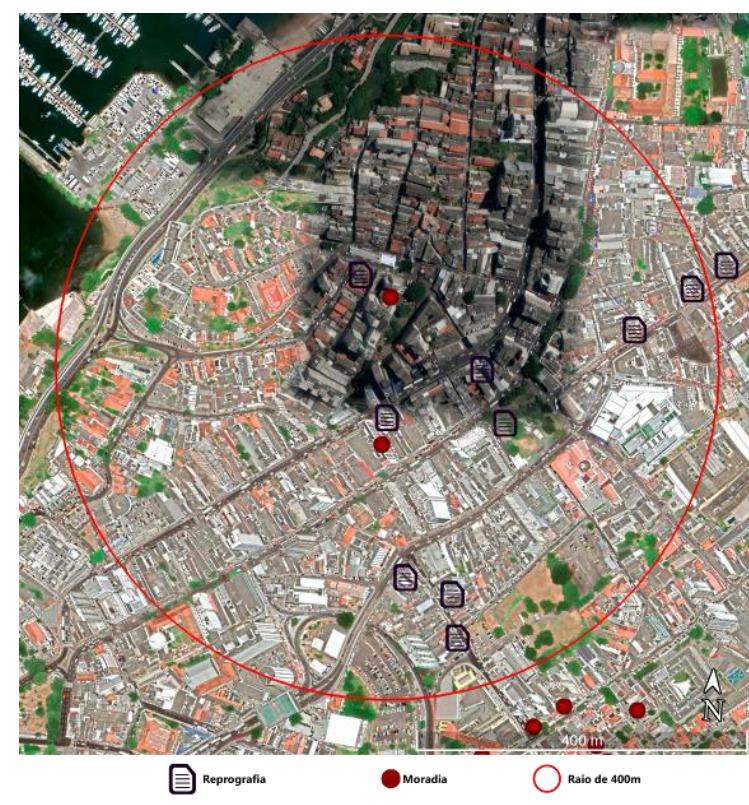

Figura 11: Oferta de equipamentos de reprografia no entorno do grupo de moradias Dois de JuIho. Fonte: Acervo dos Autores. 


\section{Considerações finais}

A expansão das universidades públicas no país, mencionada no artigo, ocasionou uma crescente demanda por moradia estudantil e por outras ações para a permanência de estudantes socialmente vulneráveis nas universidades. Esta permanência está sujeita a diversos aspectos que compõem o direito à cidade, como o direito à moradia, ao transporte, ao atendimento de saúde e a sensação de pertencimento à cidade.

Entendemos que ao analisar o contexto de uma moradia estudantil, devemos levar em consideração diversos aspectos além dos abordados neste artigo, como por exemplo a existência e a qualidade de espaços públicos, áreas verdes, equipamentos educacionais, entre outros. No entanto, devido às limitações da pesquisa, foi necessário priorizar a análise dos equipamentos de utilização cotidiana de um estudante, em relação apenas, a sua oferta.

Estes equipamentos analisados (de saúde, farmácia, mercado e reprografia), possuem algumas diferenças em sua distribuição pela cidade. Em um mesmo bairro ou localidade, pode não haver uniformidade na distribuição dos equipamentos. Exemplo disso ocorre com relação aos equipamentos de saúde no bairro dos Barris, no qual os contextos Barris e Barris 2 possuem respectivamente cinco e 6 equipamentos para atendimento especializado, enquanto o contexto Barris 3 possui dois equipamentos deste tipo. $O$ entorno das moradias localizadas no Tororó também apresenta distribuição desigual dos equipamentos de saúde. O contexto Tororó possui 6 equipamentos para atendimento especializado em seu entorno, enquanto $o$ contexto Tororó 2 possui dois equipamentos deste tipo.

Com relação ao equipamento farmácia, no bairro Garcia, o contexto Garcia possui um equipamento de farmácia e o contexto Garcia 3 possui 11 equipamentos deste tipo. Ocorre também no bairro Dois de Julho com relação ao equipamento de reprografia. O contexto Dois de Julho não possui nenhum equipamento do tipo, enquanto o contexto Dois de Julho 2 possui 9 equipamentos de reprografia.

A partir da interpretação dos gráficos, concluímos que a maioria das moradias estudantis localizadas em Salvador encontra-se inserida em contextos com boa oferta dos equipamentos aqui analisados e considerados de utilização cotidiana por estudantes. Destacamos os grupos de moradias inseridos nos bairros Barris, Brotas e
Garcia que possuem pelo menos um equipamento de cada tipo dos que foram analisados.

Assim, o local de moradia destes estudantes irá interferir na oportunidade de acesso a equipamentos urbanos. Levando em conta o que diz Lefebvre (2001, p.117-118), "o direito à cidade não pode ser concebido como um simples direito de visita ou de retorno às cidades tradicionais. Só pode ser formulado como direito à vida urbana, transformada, renovada", concluímos que ao pensar em estratégias de permanência de estudantes na universidade, deve-se levar em conta, além da qualidade das moradias construídas, a sua inserção no contexto da cidade, para que além da garantia do direito à moradia, ocorra também o direito à cidade para estes estudantes.

\section{Referências}

ASSOCIAÇÃO NACIONAL DOS DIRIGENTES DAS INSTITUIÇÕES FEDERAIS DE ENSINO SUPERIOR. V Pesquisa Nacional de Perfil Socioeconômico e Cultural dos (as) Graduandos (as) das IFES. Uberlândia, 2019. Disponível em: http://www.andifes.org.br/wp-content/uploads/2019/05/V-Pesquisa-do-Perfil-Socioecono\%CC\%82mico-dos-Estudantes-de-Graduac\%CC\%A7a\%CC\%83o-dasU.pdf. Acesso em: 28 nov. 2019.

BAUMGARTNER, Wendel Henrique. A recente expansão das universidades federais no Brasil e os impactos no espaço urbano de cidades médias da Bahia. In: XIV Simpósio Nacional de Geografia Urbana: Perspectivas e abordagens da Geografia Urbana no século XXI, set. 2015, Fortaleza.

CASTELLO, lara Regina. Bairros, loteamentos e condomínios: elementos para o projeto de novos territórios habitacionais. 1. ed. Porto Alegre: Editora UFRGS, 2008. $206 \mathrm{p}$.

COSTA, Gerson Carlos de Oliveira; OLIVEIRA, Pedro de. Moradias Estudantis: Uma política pública na consolidação do Direito à Cidade. In: urbBA[12]: A produção da cidade e captura do público: que perspectivas?, nov. 2012, Salvador. Disponível em: http://urbanismonabahia2012.blogspot.com/p/anais.html. Acesso em: 28 nov. 2019. 
CUNHA, Eudes Oliveira. Implementação da política de permanência de estudantes na Universidade Federal da Bahia. Tese (Doutorado em Educação) - Faculdade de Educação, Universidade Federal da Bahia, Salvador, 2017. Disponível em: https://repositorio.ufba.br/ri/handle/ri/24870. Acesso em: 28 nov. 2019.

GOOGLE. Google Maps. Disponível em: https://www.google.com.br/maps. Acesso em: set. 2019.

GOVERNO DO ESTADO DA BAHIA. Atendimento ao cidadão. Disponível em:

http://www.saude.ba.gov.br/atencao-a-saude/comofuncionaosus/. Acesso em: mai. 2019.

IMPERATORI, Thaís Kristosch. A trajetória da assistência estudantil na educação superior brasileira. Serviço Social \& Sociedade, São Paulo, n. 129, p. 285-303, mai./ago. 2017, Disponível em: http://www.scielo.br/pdt/sssoc/n129/0101-6628sssoc-129-0285.pdf. Acesso em: mar. 2018.

DELGADO, Juan Pedro Moreno. Pontos Notáveis. Salvador, 2019. Banco de dados em KML.

LEFEBVRE, Henri (1968). 0 direito à cidade. Tradução: Rubens Eduardo Frias. 5. Ed. São Paulo: Centauro, 2001. 146 p.

SANTOS, Elisabete. et al. (orgs.). O Caminho das Águas em Salvador: Bacias Hidrográficas, Bairros e Fontes. Salvador: CIAGS/UFBA; SEMA, 2010. 486p. Disponível em: http://www.meioambiente.ba.gov.br/arquivos/File/Publicacoes/Livros/caminhodasaguas.pdf. Acesso em: mai. 2019.

SECRETARIA MUNICIPAL DA SAÚDE DA PREFEITURA DE SALVADOR. Mapa da Saúde. Disponível em: http://www.saude.salvador.ba.gov.br/mapa-da-saude/. Acesso em: mai. 2019.

TRINDADE, Thiago Aparecido. Direitos e cidadania: reflexões sobre o direito à cidade. Lua Nova, São Paulo, n.87, p.139-165, 2012. Disponível em: https://www.scielo.br/pdf/ln/n87/07.pdf. Acesso em: jun. 2018. 